\title{
The École Polytechnique
}

(1) ut of the turbulent years of the French Revolution came important developments in mathematics. These included the founding in Paris of the École Polytechnique, where the country's finest mathematicians, including Monge, Laplace, Lagrange, and Cauchy, taught students destined to serve in military and civilian capacities. The Polytechnique's textbooks were later widely used in the United States.

Gaspard Monge (1746-1818) taught at the military school in Mézières, where he studied the properties of lines and planes in three dimensions. While investigating fortress gun emplacements during Napoleon's Egyptian expedition of 1798 , he developed general methods for projecting objects

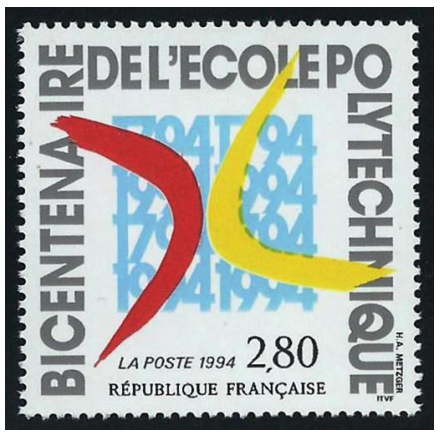

École Polytechnique

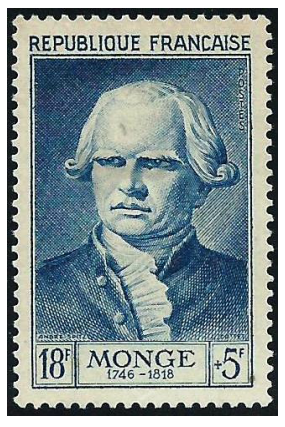

Monge

onto a plane; this subject soon became known as "descriptive geometry."

Pierre-Simon Laplace (1749-1827) wrote a celebrated text on the theory of probability and a monumental fivevolume treatise on celestial mechanics that earned him the title of "the Newton of France." Named after him are the Laplace transform of a function and Laplace's equation in mathematical physics.

Italian-born Joseph Louis Lagrange (1736-1813) wrote the first "theory of functions," in the language of power series. His Mécanique Analytique was an influential text on mechanics, and in number theory he proved that every positive integer is the sum of four perfect squares.

Shortly after the French Revolution, a commission was set up to standardize the weights and measures in France and to introduce a metric system. The chairman of this commission was Lagrange and its members included Laplace and Monge.

Augustin-Louis Cauchy (1789-1857) transformed the subject of real analysis by formalizing the concepts of limit, continuity, derivative, and integral. In addition, he almost single-handedly developed the subject of complex analysis; "Cauchy's integral formula" appears on the stamp.

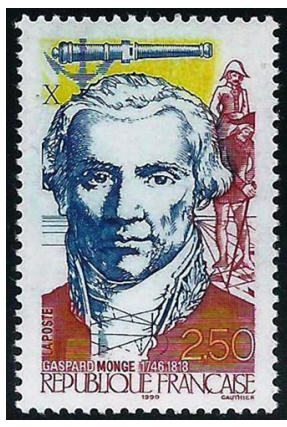

Monge

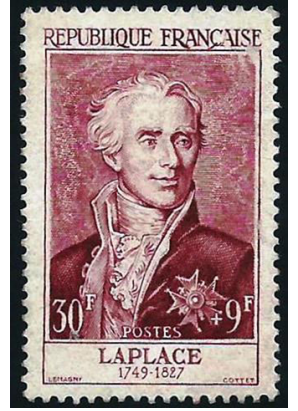

Laplace

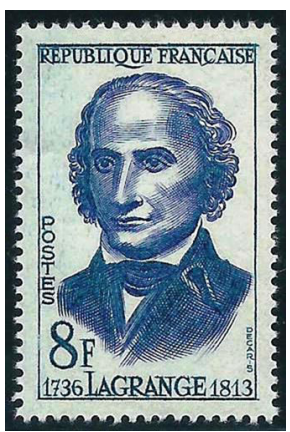

Lagrange

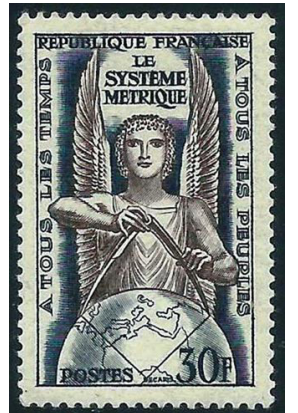

Metric system

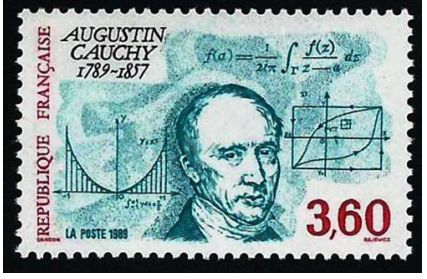

Cauchy

> Column editor's address: Robin Wilson, Mathematical Institute,

Andrew Wiles Building, University of Oxford, UK

e-mail: r.j.wilson@open.ac.uk 